https://doi.org/10.15407/ujpe65.4.321

A.P. NAUMENKO,${ }^{1}$ V.I. BORYSUK, ${ }^{1}$ M.S. IAKHNENKO, ${ }^{1}$ V.O. GUBANOV,${ }^{1}$

Y.L. SLOMINSKII, ${ }^{2}$ O.D. KACHKOVSKY ${ }^{3}$

1 Taras Shevchenko National University of Kyiv

(64/13, Volodymyrs'ka Str., Kyiv 01601, Ukraine)

2 Institute of Organic Chemistry, Nat. Acad. of Sci. of Ukraine

(5, Murmans'ka Str., Kyiv 03660, Ukraine)

${ }^{3}$ V.P. Kukhar Institute of Bioorganic Chemistry and Petrochemistry,

Nat. Acad. of Sci. of Ukraine

(1, Murmans'ka Str., Kyiv 02094, Ukraine)

\title{
PROBING OF HIGHER EXCITED STATES OF MEROCYANINE DERIVATIVES OF AZAAZULENE AND INDANDIONE BY FLUORESCENCE EXCITATION ANISOTROPY SPECTRA ${ }^{1}$
}

\begin{abstract}
This paper is dedicated to the spectral and quantum-chemical studies of higher excited states of merocyanine derivatives of azaazulene and indandione. A particular attention is paid to the analysis of fluorescence excitation anisotropy spectra of the mentioned compounds. The long-wave shift by $\approx 50 \mathrm{~nm}$ of a deep clear minimum in the fluorescence excitation anisotropy spectrum due to an elongation of the polymethine dye chromophore is established. Such shift is close in a value to the bathochromic shift of the first minimum in the anisotropy spectrum of symmetric ionic polymethine dyes, in which this minimum corresponds to the second electronic transition. The parallel spectral study and quantum-chemical calculations allowed us to correctly interpret the fluorescence excitation anisotropy spectra of merocyanines and relate the first clear minimum with the seventh electronic transition. The last resembles the second electronic transition between delocalized molecular orbitals (MO) in polymethine dyes.
\end{abstract}

Ke ywords: polymethine dyes, absorption spectra, fluorescence spectra, anisotropy of fluorescence excitation, quantum-chemical calculations.

\section{Introduction}

The study of fluorescence excitation anisotropy spectra is a useful tool for the registration of higher excited states [1], especially in the case of linear molecules where the higher electronic transitions are polarized mutually perpendicularly to the first transition.

The successful use of fluorescence excitation anisotropy spectra for both ionic polymethine dyes and their neutral derivatives, squarines and merocyanines [2-6], was provided. Thus, on the basis of combined spectral and quantum-chemical studies, it was shown that the second excited state of symmetric cationic dyes is polarized perpendicularly to the chromophore axis, resulting in its manifestation as the first deep minimum in the fluorescence excitation anisotropy

(C) A.P. NAUMENKO, V.I. BORYSUK,

M.S. IAKHNENKO, V.O. GUBANOV,

Y.L. SLOMINSKII, O.D. KACHKOVSKY, 2020 spectra [2-5]; it corresponds to the transition from the split donor level to the lower vacant orbital. The same nature of the second transition was observed in asymmetric styryls [6]. In anionic dyes, derivatives of aminocoumarin, the second transition, which is also polarized perpendicularly to the chromophore axis and detected as the first minimum in the fluorescence excitation anisotropy spectrum, on the contrary, corresponds to the transition to the second vacant, acceptor orbital [7]. At the same time, in merocyanines based on aminocoumarins, the second transition, which also reveals itself as a clear deep minimum in the anisotropy spectrum, corresponds to the transition from the second split donor orbital, similarly to cationic dyes [8]. In all these cases, the

\footnotetext{
1 The paper was presented at XXIVth Galyna Puchkovska International School-Seminar "Spectroscopy of Molecules and Crystals" (August 25-30, 2019, Odesa, Ukraine).
} 


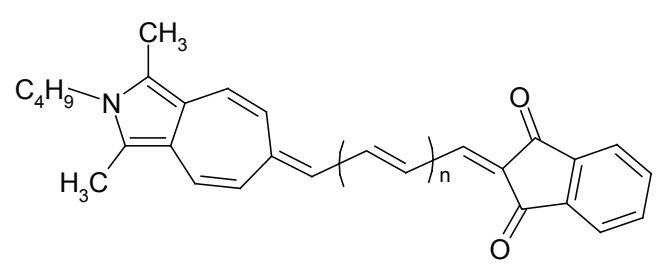

$1, \mathrm{n}=0 ; 2, \mathrm{n}=1$

Fig. 1. Chemical formulas of the studied dyes

clear minima in the anisotropy spectra correspond to the transitions, in which the orbitals involved are maximally delocalized both in the main polymethine chromophore and in the coupled system of the end groups. The assignment of spectral bands becomes much more complicated, if there are transitions that involve MO, which are localized only in the end fragments of the dye molecules. For example, a detailed study of cationic symmetric dyes, derivatives of 2azaazulene, showed that two occupied orbitals located below the highest occupied MO (HOMO - 1 and $\mathrm{HOMO}-2$ ) are the localized orbitals and have a node on the carbon atom of the end group that is bounded to the polymethine chain, so they are not conjugated with the polymethine chromophore. The electronic transitions with their participation are accompanied by a significant charge transfer, and the dipole moment of such transition (and, accordingly, the oscillator strength) is small [9-11]. As a result of such change in the nature of the electronic transition, it manifests itself in the anisotropy spectra not as a clear minimum, but only as a small minimum; a distinct assignment of such bands became possible only with parallel quantum-chemical calculations of local transitions [9]. Similarly, the manifestation of local transitions as fuzzy minima was found for symmetric cationic dyes with different chromophore lengths, when quinoline residues were contained as end groups [12].

Concerning another type of possible transitions such as $\mathrm{n} \rightarrow \pi^{*}$-transitions, in which lone pairs (nMOs) are involved, it can be assumed that they unlikely appear in the anisotropy spectra, since they are forbidden by symmetry: n-MOs are perpendicular to the $\pi$-orbitals.

This paper presents the results of the spectral and quantum-chemical studies of higher excited states of merocyanines $\mathbf{1}$ and $\mathbf{2}$ shown in Fig. 1, which contain a 2-azaazulene donor end group that generates a localized occupied orbital, as well as the indandione residue that produces both localized MOs and n-MOs due to the lone pairs of oxygen atoms.

\section{Methods of Experiments and Calculations}

The synthesis of compounds $\mathbf{1}$ and $\mathbf{2}$ was described previously [13].

The absorption spectra were recorded with a Shimadzu UV-3100 spectrophotometer in acetonitrile and ethylene glycol solvents of the spectral purity grade.

The spectra of fluorescence and the fluorescence excitation anisotropy spectra were measured by using a Varian Cary Eclipse fluorescence spectrophotometer in a viscous solution to prevent the rotational reorientation and at low concentrations $\left(\mathrm{C}=10^{-6} \mathrm{M}\right)$ to avoid the overflow.

Quantum-chemical calculations. The geometry optimization was performed by a non-empirical method DFT/6-31G(d,p)/CAM-B3LYP (Gaussian $03[14])$; characteristics of electronic transitions were calculated using the method (TD/DFT/6$31 \mathrm{G}(\mathrm{d}, \mathrm{p}) / \mathrm{CAM}-\mathrm{B} 3 \mathrm{LYP})$ and semiempirical method ZINDO. Of course, the calculations failed to achieve a perfect match of the calculated and experimental data (which is typical of these approximations [15$17]$ ); however, this is sufficient for a correct analysis of the nature of electronic transitions.

\section{Results and Discussion}

The calculated energies of frontier HUMO and LUMO, as well as MO closest to them, are given in Table 1, and the characteristics of electronic transitions - in Table 2. The orbital shapes for merocyanine with longer polymethine chain, $\mathbf{2}, \mathrm{n}=1$, are presented in Fig. 2.

The measured spectra of absorption, fluorescence, fluorescence excitation, and anisotropy of fluorescence excitations of two merocyanines $\mathbf{1}$ and $\mathbf{2}$ are shown in Fig. 3. From the two lowest electron transitions, the first one manifests itself in the absorption/fluorescence spectra as a narrow high-intensity band in the visible region, while the energy of the second transition can be obtained from the fluorescence excitation anisotropy spectrum.

As shown in Fig. 3, the relatively narrow and highly intense band with a typical vibrational peak, which is shifted by $\approx 1700 \mathrm{~cm}^{-1}$ to longer wavelengths from the maximum of the main absorption band, 
Table 1. Energies and types of frontier and close orbitals of merocyanines 1 and 2

\begin{tabular}{|c|c|c|c|c|}
\hline \multirow{2}{*}{$\mathrm{MO}$} & \multicolumn{2}{|c|}{$\mathbf{1}, \mathrm{n}=0$} & \multicolumn{2}{|c|}{$\mathbf{2}, \mathrm{n}=1$} \\
\hline & Type & $\varepsilon, \mathrm{eV}$ & Type & $\varepsilon, \mathrm{eV}$ \\
\hline $\mathrm{LUMO}+3$ & & 0.65 & Localized (Aaz) MO & 0.70 \\
\hline $\mathrm{LUMO}+2$ & & 0.47 & Delocalized MO & 0.13 \\
\hline $\mathrm{LUMO}+1$ & Localized (Ind) MO & -0.19 & Localized (Ind) MO & -0.25 \\
\hline LUMO & Delocalized MO & -1.37 & Delocalized MO & -1.46 \\
\hline HOMO & Delocalized MO & -5.89 & Delocalized MO & -5.74 \\
\hline HOMO - 1 & Localized (Aaz) & -6.85 & Localized (Aaz) MO & -6.80 \\
\hline $\mathrm{HOMO}-2$ & & -7.78 & $\mathrm{n}-\mathrm{MO}$ & -7.50 \\
\hline $\mathrm{HOMO}-3$ & & -7.92 & Delocalized MO & -7.84 \\
\hline $\mathrm{HOMO}-4$ & & -8.41 & Localized (Ind) MO & -8.44 \\
\hline
\end{tabular}

Designation: Aaz - azaazulene donor end group; Ind - indandione acceptor end group; n-MO - orbital of a lone pair of oxygen atoms.

Table 2. Calculated characteristics of electronic transitions of merocyanines 1 and 2

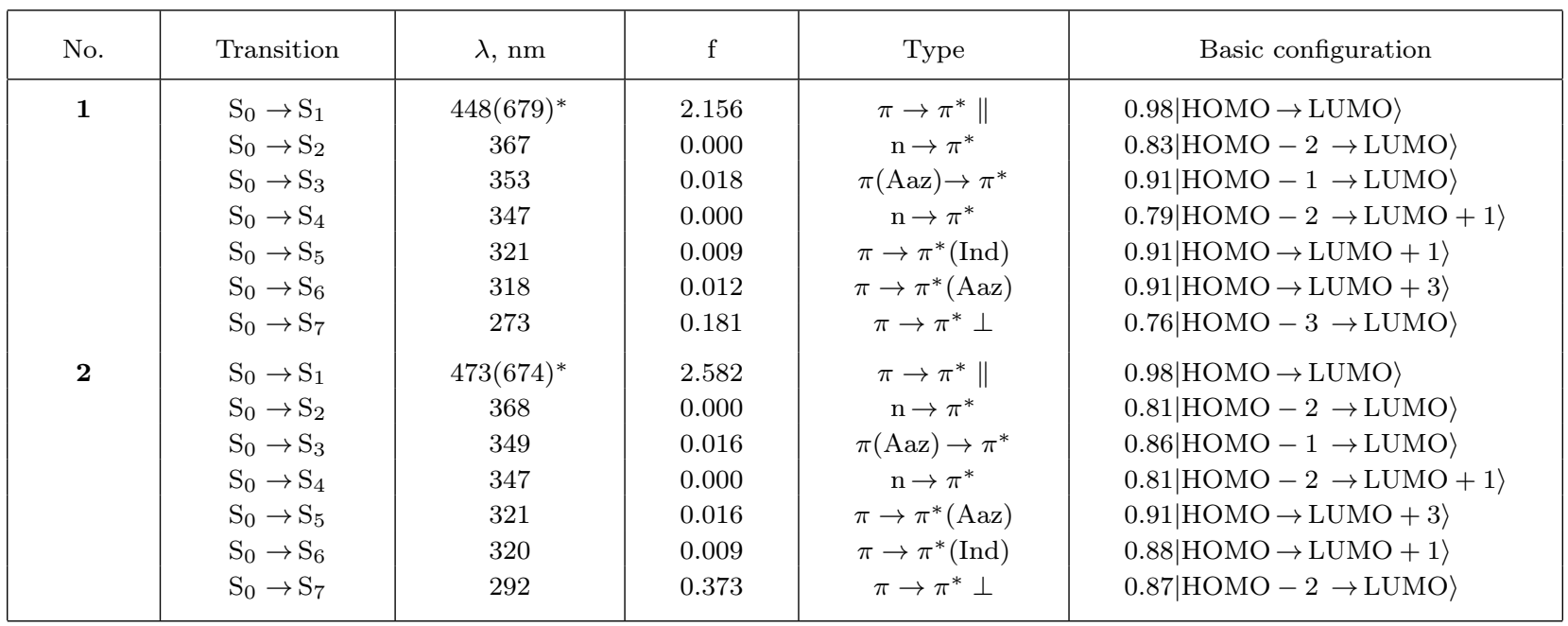

Note: ${ }^{*}$ data in brackets are calculated using the ZINDO/S method with the parameter OWF $=0.2$ and taking 50 single-excited configurations into account.

Designation: $\|$ is the transition polarized in parallel to the chromophore, $\perp$ is the transition polarized perpendicularly to the chromophore.

is observed in the absorption spectrum of merocyanine 1. A narrow peak with a small Stokes shift, $\Delta \nu_{S} \approx 530 \mathrm{~cm}^{-1}$, appears in the fluorescence spectrum, which indicates small changes in the equilibrium geometry of the chromophore upon the excitation. By magnitude, these changes are close to the Stokes shifts in the spectra of symmetric polymethine dyes $[6,9,12]$. The anisotropy spectrum demonstrates fuzzy regions at about $450-500 \mathrm{~nm}$ and a clear deep minimum at $410 \mathrm{~nm}$.

The elongation of the polymethine chain is accompanied by a bathochromic shift of the fluorescence excitation band by $\approx 106 \mathrm{~nm}$, while the absorption band significantly changes its shape. The distance between the maximum of the absorption band and the maximum of the fluorescence band is $\approx 2200 \mathrm{~cm}^{-1}$, while the distance between the maximum of the fluorescence excitation band and the maximum of the fluorescence band is $\approx 527 \mathrm{~cm}^{-1}$, which practically coincides with the Stokes shift $\Delta \nu_{S}$ for a shorter molecule. So, it can be assumed that the intense peak in the absorption spectrum of dye $\mathbf{2}$ corresponds to the vibrational transition $0 \rightarrow 1^{\prime}$; quantitative evaluation of its magnitude (as the distance between the 


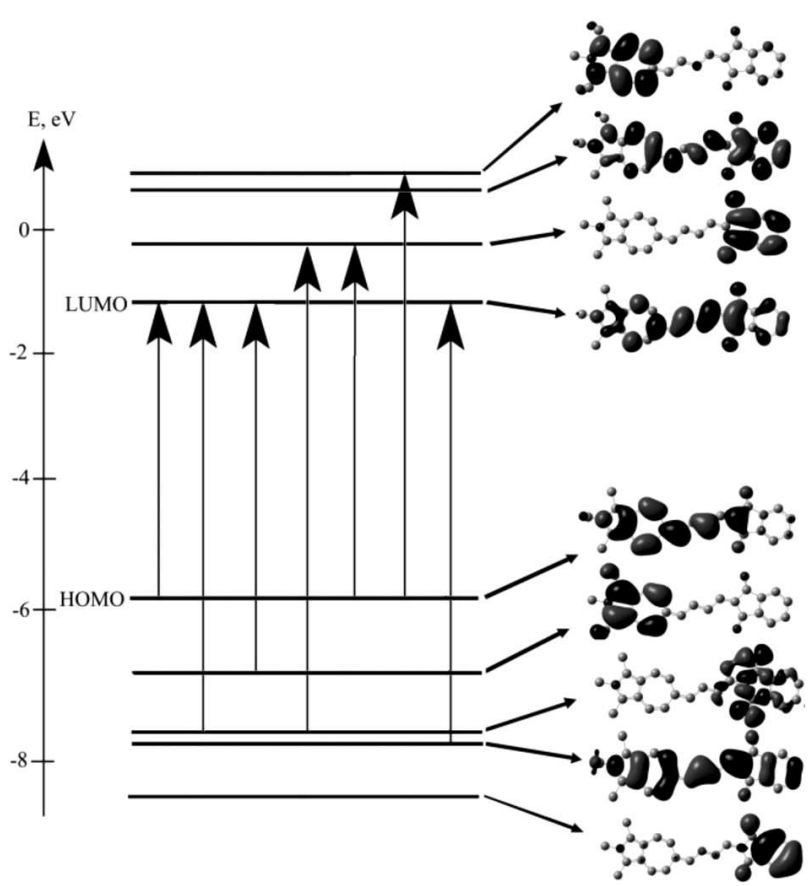

Fig. 2. Shapes of the frontier and close MOs of merocyanine $2(\mathrm{n}=1)$

intense peak in the absorption spectrum (640 nm) and the peak in the fluorescence excitation spectrum $(718 \mathrm{~nm}))$ is $\approx 1700 \mathrm{~cm}^{-1}$ and, therefore, practically coincides with the distance between the basic $0 \rightarrow 0^{\prime}$ and the next $0 \rightarrow 1^{\prime}$ vibrational transitions for dye $\mathbf{1}$ with a shorter chromophore. The comparison of the anisotropy spectra in Fig. 3, $a$ and $3, b$ shows that the elongation of the chromophore leads to a red shift of the deep clear minimum by $\approx 40-50 \mathrm{~nm}$. This value is close to the bathochromic shift of the first minimum in the anisotropy spectra of symmetric ion polymethine dyes, in which this minimum corresponds to the second electronic transition $\mathrm{S}_{0} \rightarrow \mathrm{S}_{2}[2-10]$.

In order to provide the assignment of bands of the obtained spectra correctly, we have analyzed the nature of the lower electronic transitions of molecules $\mathbf{1}$ and $\mathbf{2}$, which are observed in the UV and visible regions. At first, we examine, in detail, the shape of the frontier and close MOs that form the lower electronic transitions: their localizations are shown in Table. 1. As an example, MO's shape of merocyanine with an extended chromophore is shown in Fig. 2.

As can be seen, both frontier orbitals of the considered dyes, HOMO and LUMO, are delocalized almost all over the conjugated system; the occu-

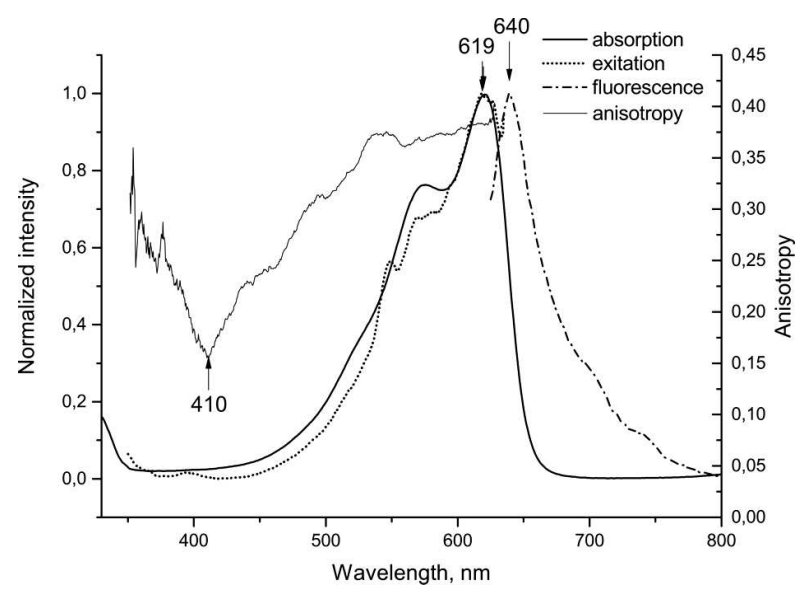

$a$

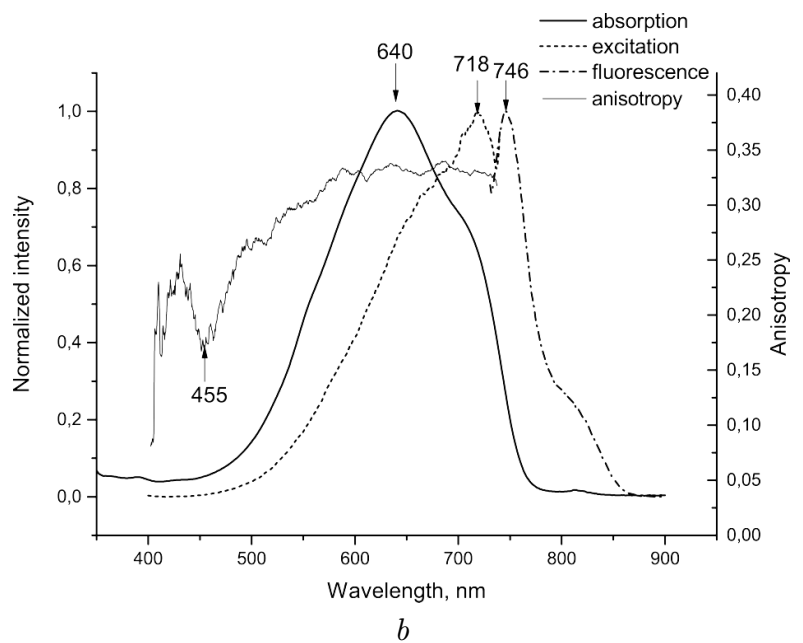

Fig. 3. Absorption, fluorescence, fluorescence excitation, and fluorescence excitations anisotropy spectra of dyes $\mathbf{1}(a)$ and $2(b)$

pied $\mathrm{HOMO}-3$ and unoccupied LUMO +2 are also delocalized. All other orbitals shown in Fig. 2 and listed in Table 1 are localized: (i) the occupied $\mathrm{HOMO}-1$ and unoccupied LUMO +3 are localized $\pi$-orbitals formed by the atoms of donor azazulene's end group; (ii) the occupied HOMO-4 and unoccupied $\mathrm{LUMO}+1$ are localized only in the acceptor residue of indandione. Among the occupied orbitals, one orbital from the 4 split ones, which are based on the lone electron pairs of two oxygen atoms of indandione, is highly localized. This orbital lies in the plane of the molecule and is orthogonal to the $\pi$-electron system of dye molecules.

With regard for the classification of orbitals, it is possible to identify the types of lower electronic tran- 
sitions and to analyze the possibility of their spectral detection. As can be seen from Table 2, the first transition, $\mathrm{S}_{0} \rightarrow \mathrm{S}_{1}$, is almost completely described by a configuration of singly occupied frontier orbitals. Since both MOs are delocalized, the transition has a large oscillator strength. This is consistent with the high intensity of the long-wave absorption band in the absorption spectrum. This transition is polarized along the polymethine chain. The comparison of the calculated wavelength, $\lambda_{\text {calc }}$, (Table 2) with the experimental position of the absorption band maximum (Fig. 3) shows a significant difference. The use of a semiempirical calculation method with varying the OWF (overlap weight factor) gives a much closer value to the spectral one; and the order of arrangement of the excited states and their nature do not change. So, when continuing to use the data obtained by the non-empirical method for the analysis, one should keep in mind that these data do not have the best correlation of the calculated values with the experimental ones.

The elongation of the polymethine chain to one vinyl group causes a red shift of the absorption maximum in the spectrum of dye $\mathbf{2}\left(0 \rightarrow 0^{\prime}\right.$ vibrational transition) by about $90-100 \mathrm{~nm}$, while the calculation by the non-empirical TD DFT method gives a much smaller value of this shift to be $25 \mathrm{~nm}$; the semiempirical ZINDO/S method gives a larger value of $95 \mathrm{~nm}$.

According to our calculations, the next transition, $\mathrm{S}_{0} \rightarrow \mathrm{S}_{2}$, is associated with the participation of n$\mathrm{MO}$, so it is forbidden: the oscillator strength is $\mathrm{f}_{2}=0.000$. Therefore, it does not manifest itself in either the absorption spectrum or the anisotropy spectrum. Table 2 shows that the fourth transition, $\mathrm{S}_{0} \rightarrow \mathrm{S}_{4}$, is also the forbidden $\mathrm{n} \rightarrow \pi^{*}$ transition in both dyes. The transition of this type is almost insensitive to the length of the chromophore.

The third transition is realized by the electron jump from the localized MO (HOMO - 1), which includes only atoms of azaazulene end residue, to the delocalized LUMO; the calculated oscillator strength, $\mathrm{f}_{4}$, is two orders of magnitude lower than in the case of the first transition, so it is not observed in the absorption spectrum. In the anisotropy spectrum, this transition, as well as other local ones, can be associated with unclear areas at the region around $500 \mathrm{~nm}$. The precise analysis of the data from Table 2 shows that the vacant $\mathrm{MO}$, localized only on the azaazulene end group, participates in the transition $\mathrm{S}_{0} \rightarrow \mathrm{S}_{6}$ in the case of merocyanine $\mathbf{1}$ with a shorter chain. While it turns to lower transition: $\mathrm{S}_{0} \rightarrow \mathrm{S}_{5}$ along with the elongation of the chromophore, it is almost insensitive to the number of vinyl groups in the polymethine chain. The oscillator strength is also two orders of magnitude smaller than $\mathrm{f}_{1}$; therefore, it is also practically not observed in the anisotropy spectra.

The calculations give the same small oscillator strength for another local transition with the participation of a vacant $\mathrm{MO}(\mathrm{LUMO}+1)$, localized only on the acceptor residue of indandion: the transition $\mathrm{S}_{0} \rightarrow \mathrm{S}_{5}$ in dye $\mathbf{1}$; the transition $\mathrm{S}_{0} \rightarrow \mathrm{S}_{6}$ in dye $\mathbf{2}$. For the same reasons, as mentioned above, a clear spectral manifestation of this type of transition is unlikely. Table 2 shows that the elongation of the chromophore is accompanied by the inversion of local transitions of different types.

Finally, the seventh transition, $\mathrm{S}_{0} \rightarrow \mathrm{S}_{7}$, can be classified as a delocalized transition or as a transition between two delocalized orbitals similar to the first transition $\mathrm{S}_{0} \rightarrow \mathrm{S}_{1}$. According to the calculations, this transition is polarized perpendicularly to the chromophore (unlike the transition $\mathrm{S}_{0} \rightarrow \mathrm{S}_{1}$ ) and, therefore, to the first transition. Its oscillator strength is much higher than for local transitions. However, it is obviously too small to be observed as a single band with sufficient intensity in the absorption spectrum. Although, this transition is clearly observed in the anisotropy spectrum of fluorescence excitation as a relatively deep first minimum in the 400$450 \mathrm{~nm}$ region. This is similar to the anisotropy spectrum of cationic and anionic polymethine dyes, where such a minimum also corresponds to the transition between delocalized MOs that polarized perpendicularly to the chromophore.

The calculated distance between delocalized transitions, $\mathrm{S}_{0} \rightarrow \mathrm{S}_{1}$ and $\mathrm{S}_{0} \rightarrow \mathrm{S}_{7}$, is $175-180 \mathrm{~nm}$ and is slightly smaller than the experimental distance between the positions of the maximum of the longwavelength absorption band and the deep minimum in the anisotropy spectrum, which is $200-250 \mathrm{~nm}$. However, it can be stated that the calculated electronic transitions correspond by their characteristics to the transitions detected experimentally.

\section{Conclusions}

Thus, for the first time, the spectral studies and quantum-chemical calculations allowed us to correctly in- 
terpret the anisotropy spectra of fluorescence excitation of merocyanines. The first clear minimum is assigned to the seventh transition, which by its nature is similar to the second transition between delocalized MOs of polymethine dyes and is polarized perpendicularly to the first transition. The electronic transitions (third, fifth, and sixth) that involve the participation of localized orbitals are either weak or completely inactive in the anisotropy spectra.

1. J.R. Lakowicz. Principles of Fluorescence Spectroscopy (Academic/Plenum, 1999).

2. R.A. Negres, O.V. Przhonska, D.J. Hagan, E.W. Van Stryland, M.V. Bondar, Yu.L. Slominsky, A.D. Kachkovski. IEEE J. Selected Topics Quantum Electron 7, 849 (2001).

3. R.S. Lepkowicz, O.V. Przhonska, J.M. Hales, D.J. Hagan, E.W. Van Stryland, M.V. Bondar, Yu.L. Slominsky, A.D. Kachkovski. Excited-state absorption dynamics in polymethine dyes detected by polarization-resolved pumpprobe measurements. Chem. Phys. 286, 277 (2003).

4. O.V. Przhonska, L.A. Padilha, D.J. Hagan, E.W. Van Stryland, K.D. Belfield, M.V. Bondar, Yu.L. Slominsky, A.D. Kachkovski. Two-photon anisotropy: analytical description and molecular modeling for symmetrical and asymmetrical organic dyes. Chem. Phys. 321, 257 (2006).

5. O. Przhonska, S. Webster, L. Padilha, H. Hu, A. Kachkovski, D. Hagan, E.V. Stryland. Two-photon absorption in near-IR conjugated molecules: design strategy and structure-property relations. In: Advanced Fluorescence Reporters in Chemistry and Biology I: Fundamentals and Molecular Design, Springer Series in Fluorescence, Vol. 8, (Springer, 2010), pp. 105-147.

6. A.V. Stanova, A.B. Ryabitsky, V.M. Yashchuk, O.D. Kachkovsky, A.O. Gerasov, Ya.O. Prostota, O.V. Kropachev. Asymmetry in ground and excited states in styryls and methoxystyryls detected by NMR (13 C), absorption, fluorescence and fluorescence excitation spectroscopy. J. Molec. Struct. 988, 102 (2011).

7. L.A. Padilha, S. Webster, O.V. Przhonska, H. Hu, D. Peceli, J.L. Rosch et al. Efficient two-photon absorbing acceptor-p-acceptor polymethine dyes. J. Phys. Chem. A 114, 6493 (2010).

8. L.A. Padilha, S. Webster, O.V. Przhonska, H. Hu, D. Peceli, J.L. Rosch et al. Nonlinear absorption in a series of donor-p-acceptor cyanines with different conjugation lengths. J. Mater. Chem. 19, 7503 (2009).

9. O.V. Przhonska, H. Hu, S. Webster, J.L. Bricks, A.A. Viniychuk, A.D. Kachkovski, Yu.L. Slominsky. Electronic transitions in a series of 2-azaazulene polymethine dyes with different $\pi$-conjugation lengths. Chem. Phys. 411, 17 (2013).

10. O.O. Viniychuk, S.M. Levchenko, O.V. Przhonska, O.D. Kachkovsky, Yu.L. Bricks, M.O. Kudinova, Yu.P. Kovtun, Ye.M. Poronik, M.P. Shandura, O.I. Tol- machev. Electronic transitions in polymethine dyes involving local and delocalized levels. J. Molec. Struct. 1060, 30 (2014).

11. J.L. Bricks, A.D. Kachkovskii, Yu.L. Slominskii, A.O. Gerasov, S.V. Popov. Molecular design of near infrared polymethine dyes: A review. Dyes and Pigments 121, 238 (2015).

12. O. Chernega, S. Levchenko, A. Ryabitskii, A. Gerasov, O. Kachkovskii, Yu. Yagupolskii. Nature of the lowest electron transitions of thia- and quinocyanines with fluorinated polymethine chain. Dyes and Pigments. 123, 176 (2015).

13. J.L. Bricks, A.V. Stanova, A.B. Ryabitsky, V.M. Yashchuk, A.D. Kachkovsky. Studies of 2-azaazulenium derivatives 3: The nature of electron transitions and spectral properties of styryl dyes containing terminal groups of different types. J. Molec. Struct. 1033, 215 (2013).

14. M.J. Frisch, G.W. Trucks, H.B. Schlegel, et al. GAUSSIAN 09 Revision B.05 (GAUSSIAN, 2003).

15. J. Fabian. TDDFT-calculations of Vis/NIR absorbing compounds. Dyes and Pigments 84, 36 (2009).

16. S Karaca, N. Elmaci. A computational study on the excited state properties of a cationic cyanine dye: TTBC. Comput. Theor. Chem. 964, 160 (2011).

17. D. Jacquemin, Ya. Zhao, R. Valero, C. Adamo, I. Ciofini, D.G. Truhlar. Verdict: Time-dependent density functional theory "Not guilty" of large errors for cyanines. J. Chem. Theory Comput. 8, 1255 (2012).

Received 17.12.19

\section{А.П. Науменко, В.І. Борисюк,}

М.С. Яхненко, В.О. Губанов, Ю.Л. Сломінсъкий

\section{ЗОНДУВАННЯ ВИЩИХ ЗБУДЖЕНИХ}

СТАНІВ ЗА ДОПОМОГОЮ СПЕКТРІВ АНІЗОТРОПIÏ ЗБУДЖЕННЯ ФЛЮОРЕСЦЕНЦЇ В МЕРОЦАНІНАХ, ПОХІДНИХ АЗААЗУЛЕНА ТА ІНДАНДІОНА

$\mathrm{P}$ е $з$ ю м е

Дана робота присвячена спектральному та квантово-хімічному дослідженню вищих збуджених станів мероціанінів, похідних азаазулена та індандіона. Особлива увага приділена аналізу спектрів анізотропії збудження флюоресценції даних сполук. Встановлено, що подовження хромофора поліметинового барвника викликає довгохвильове зміщення глибокого чіткого мінімуму в спектрі анізотропії збудження флюоресценції на 50 нм, що за своїм значенням близьке до батохромного зсуву першого мінімуму в спектрі анізотропії симетричних йонних поліметинових барвників, в яких даний мінімум відповідає другому електронному переходові. Паралельне спектральне дослідження та квантовохімічне моделювання дозволило коректно інтерпретувати спектри анізотропії збудження флюоресценції мероціанінів і пов'язати перший чіткий мінімум з сьомим електронним переходом, який за своєю природою нагадує другий електронний перехід в поліметинових барвниках між делокалізованими МО. 